\title{
Improved Predictive Current Control for Three-Phase High Power Factor AC-DC Boost Converter
}

\author{
Zhongjiu Zheng ${ }^{1,2}$ \\ ${ }^{1}$ Marine Engineering College, Dalian Maritime University, Dalian, China, 116026 \\ ${ }^{2}$ Research Institute of China CNR Corporation Limited, Beijing, China, 100078 \\ e-mail:zhengzhongjiu@163.com
}

\begin{abstract}
This paper presents a improved predictive current control of three-phase AC-DC PWM converter, which achieves unity power factor, harmonics elimination and DC-bus-voltage constant. This paper focuses on predictive current control strategy of which the control principle and the reason of static phase error existing in the AC side current are studied. And the paper presents improved predictive current control strategy, which solves the problem of static phase error existing in the AC side current in traditional predictive current control strategy using periodic phase information of voltage. The proposed three-phase AC-DC PWM converter was tested both in simulations and experiments. Results have proved excellent performance and verify the validity of the control system.
\end{abstract}

Keywords- PWM rectifier; improved predictive current; power factor; control strategy

\section{INTRODUCTION}

Using energy without pollution and efficiently is widely concerned around the world now. Traditional diode rectifier and phase-controlled rectifier need lots of reactive power provided by power grid, which will bring serious harmonic pollution to grid, affect the grid operating safely and other electronic equipment operating normally, and the effective utilization of energy will be reduced too. PWM rectifier has many advantages such as low current harmonics of grid side, unity power factor, reversibility of energy, DC voltage controlled, and so on, which will realize the "green conversion" of energy ${ }^{[1-4]}$. PWM rectifier can solve the problem of harmonics and reactive power essentially, and has broad application prospects in the fields of high-power uninterruptible power supply, four-quadrant $\mathrm{AC}$ drives, traditional power system generation product, reactive power compensation, solar power generation and other areas as well as AC and DC driving system.

Many research results focusing on the control strategies have been presented ${ }^{[5-7]}$. The approaches such as hysteresis current control(HCC), fuzzy logic control (FLC), slidingmode control (SMC), d-q transformation, one-cycle control, are employed to maintain the stability and provide high speed dynamic response of the three-phase PWM converter system. However, some of these methods are practically inapplicable for their complexity, computational time, sensitivity to machine parameters and so on. The control system that adopts predictive current control in two-dimensional stationary $(\alpha-\beta)$ frame can be simplified. Predictive current control(PCC) of three-phase AC-DC PWM converter, which achieves unity power factor, harmonics elimination and DC-bus-voltage constant.PPC makes real current can following the reference current in one switching period and switching frequency keeps constant., which calculates the reference current of next switching period with predictive method. ${ }^{[8-}$ ${ }^{11]}$ This method keeps the fast response merit. But traditional predictive current has the problem of static phase error existing in the AC side current.

This paper focuses on predictive current control strategy of which the control principle and the reason of static phase error existing in the AC side current are studied. And the paper presents improved predictive current control strategy, which solves the problem of static phase error existing in the $\mathrm{AC}$ side current in traditional predictive current control strategy using periodic phase information of voltage.

\section{TRADITIONAL PREDICTIVE CURRENT CONTROL}

principle of control

The Structure diagram of three-phase voltage source PWM rectifier based on PCC is shown in Fig .1 The PI regulator output the amplitude of reference current $I_{m}^{*}$ using difference value between reference voltage $v_{d c}^{*}$ and real voltage $v_{d c}$ of DC-bus-voltage. Reference current $\left(i_{\alpha}^{*}, i_{\beta}^{*}\right)$ in two-dimensional stationary $(\alpha-\beta)$ frame can be achieved by multiplying amplitude of reference current $I_{m}^{*}$ by phase information of grid voltage $(\sin \theta)$.The AC side voltage $\left(u_{\alpha}^{*}, u_{\beta}^{*}\right)$ can be calculated by grid voltage and the inductive voltage, which according to Variation of current. The state of the switch of the next period can be calculated by SVPWM algorithm using AC side voltage and DC-busvoltage. 


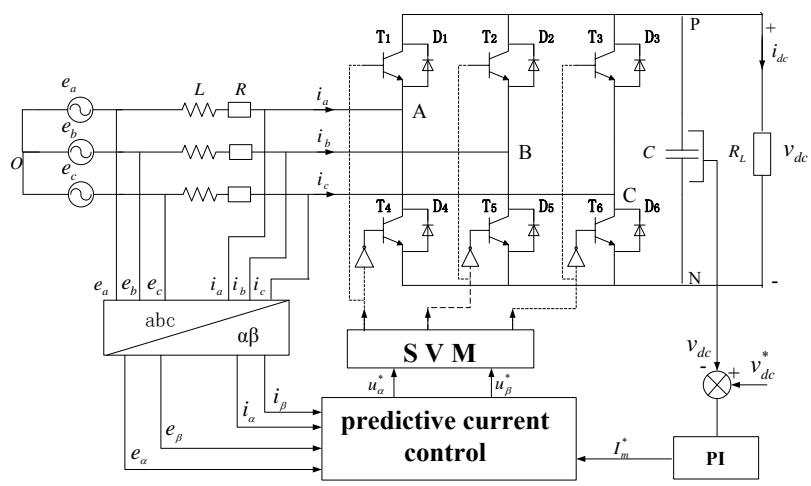

Figure 1. Structure of three-phase voltage source PWM rectifier based on PCC

Principle of predictive current control is shown in Fig. 2 .

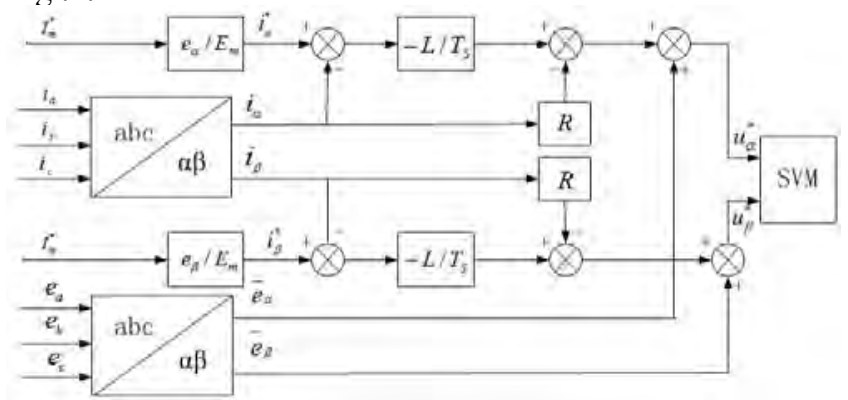

Figure 2. Principle of predictive current control

In predictive current control, the reference current be composed of amplitude of reference current $I_{m}^{*}$ and phase information of grid voltage $(\sin \theta)$, which is result of dividing sampling value of grid voltage by amplitude inside of calculating of phase angle of grid voltage. When the system is running in unit power factor, this method can simplify the control algorithm and avoid the trigonometric function calculations. But it can't realize the power factor angle adjustment without calculating of phase angle.

\section{Analysis of static phase error in PCC}

The control system that adopts predictive current control in two-dimensional stationary $(\alpha-\beta)$ frame can realize AC current sinusoidal, small amount of calculation and higher control precision. But traditional predictive current has the problem of static phase error existing in the AC side current, control variable in the present period is calculated by last period. The cause of static phase error is analyzed by adopting the method of vector diagram in following.

With phase A, for example, when the system is running in unit power factor, vector relation of AC side is shown in Fig.3.

From principle of conservation of power, when input DC-bus-voltage $v_{d c}$ is determined, the amplitude of AC current $i_{a}$ is determined. when the system is running in unit power factor, the AC current $i_{a}$ follow the phase of grid voltage, and the amplitude and phase of AC inductive voltage $u_{L a}$ is determined in Fig .3.

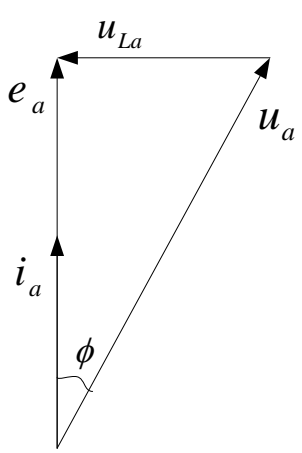

Figure 3. Vector relation of $\mathrm{AC}$ side

AC inductive voltage:

$$
\begin{gathered}
u_{L a}=L \frac{d i_{a}}{d t}=L \frac{i_{a}^{*}-i_{a}}{T_{S}}=\frac{L}{T_{S}} \cdot \Delta i_{a} \\
\Delta i_{a}=\frac{u_{L a} \cdot T_{S}}{L}
\end{gathered}
$$

In (1) and (2), $T_{S}$ is the control period, $i_{a}^{*}$ is reference current of next period in traditional predictive current control. Fig .4 shows the vector relation of reference current and real current.

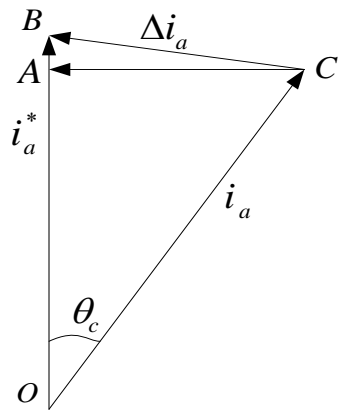

Figure 4. Vector relation of reference current and actual current

In Fig $.4,\left|i_{a}^{*}\right|=O B,\left|i_{a}\right|=O C,\left|\Delta i_{a}\right|=B C$, $O B=O C$.

$$
\Delta i_{a}=i_{a}^{*}-i_{a}=B C
$$

When the control frequency is higher enough, $B C \approx A C$.

$$
\sin \theta_{c} \approx \frac{\Delta i_{a}}{i_{a}}
$$

Substituting (2) to (4):

$$
\sin \theta_{c} \approx \frac{u_{L a} \cdot T_{S}}{L \cdot i_{a}}=\frac{L \cdot \omega \cdot i_{a} \cdot T_{S}}{L \cdot i_{a}}=\omega \cdot T_{S}
$$

When $\theta_{c}$ is small,

$$
\theta_{c}=\sin \theta_{c}=\omega \cdot T_{S}
$$

The static phase error is inversely proportional to control of frequency. Because static phase error existing in the AC side current affect the power factor of PWM rectifier, it must be compensated making the phase of $\mathrm{AC}$ current tracking real phase of grid voltage. 


\section{IMPROVED PREDICTIVE CURRENT CONTROL}

The traditional predictive current has the problem of static phase error existing in the AC side current. And the static phase error is inversely proportional to control of frequency. When control frequency is constant, the phase error is constant value. In order to compensation for phase angle, a constant compensation angle can be added to the phase angle of reference current. The reference current is:

$$
i^{*}(t)=I_{m} \sin \left(\omega t+\theta+\theta_{c}\right)
$$

The traditional predictive current control can simplify the control algorithm and avoid the trigonometric function calculations. But the phase information of grid voltage $(\sin \theta)$ is the result of dividing sampling value of grid voltage by amplitude inside of calculating of phase angle. The phase information is:

$$
\sin (\omega t+\theta)=\frac{u(t)}{U_{m}}
$$

So the reference current is:

$$
i^{*}(t)=I_{m} \sin (\omega t+\theta)=I_{m} \cdot \frac{u(t)}{U_{m}}
$$

This simplified method for calculating phase information can not implement the compensation for phase angle of $\mathrm{AC}$ current. For implementing phase compensation, the phase angle of grid voltage must be calculated.

$$
\varphi=\arcsin \frac{u(t)}{U_{m}}
$$

The reference current compensated phase angel is:

$$
i^{*}(t)=I_{m} \sin \left(\varphi+\theta_{c}\right)
$$

The above compensation arithmetic need two calculations for trigonometric function, and there are six calculations for trigonometric function in three-phase system. In practical application, the calculations for trigonometric function increase the amount of calculation of the algorithm, and take up a lot of microprocessor memory. It adverse to digitization for control algorithm of static phase error compensation of current in traditional predictive current control.

For simplifying the control algorithm and avoiding the trigonometric function calculations, this paper presents improved predictive current control strategy, which solves the problem of static phase error existing in the AC side current using periodic phase information of voltage and realizes the power factor Angle adjustment without calculating of phase angle.

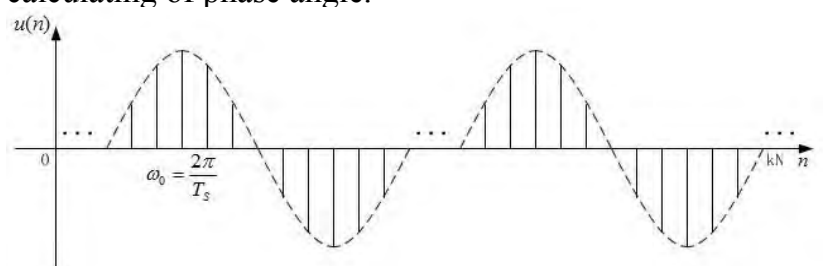

Figure 5. Discrete signal of voltage

In practical application, the realization of the control system mainly uses the microprocessor, so signal processing is discretization. First, the AC voltage and current are dispersed. The grid voltage is periodic sine wave, When control frequency is constant, The number of sampling is constant in every period. So the curve of the sampling points are periodic discrete points in Fig .5.

The number of sampling points in one period is:

$$
N=\frac{f_{S}}{f}
$$

In (12), $f_{S}$ is sample frequency; $f$ is fundamental frequency of voltage. the discretization grid voltage signal is:

$$
u(n)=U_{m} \sin \left(k N+\omega_{0} n\right)
$$

In (13), $\omega_{0}=\frac{2 \pi}{T_{S}}, k=0,1,2 \ldots, n=0,1,2 \ldots, N-1$. Now, the discretization reference current signal is:

$$
i(n)^{*}=I_{m}^{*} \sin \left(k N+\omega_{0} n\right)
$$

When compensations of phase angle is $m=\left\|\frac{\theta_{c}}{\omega_{0}}\right\|$, in order to realize static phase error compensation of $\mathrm{AC}$ current, the reference current is:

$$
i(n)^{*}=I_{m}^{*} \sin \left[k N+\omega_{0}(n+m)\right] \quad(m=0,1,2 \ldots, N-1)
$$

The discrete sine signal is periodic, so

$$
\sin \left[k N+\omega_{0}(n+m)\right]=\sin \left[(k-1) N+\omega_{0}(n+m)\right]
$$

Therefore, Compensated reference current is:

$$
i(n)^{*}=I_{m}^{*} \sin \left[(k-1) N+\omega_{0}(n+m)\right]
$$

If the phase information of grid voltage in last period has been stored in the process of sampling, $\sin \left[k(N-1)+\omega_{0}(n+m)\right]$ could be retrieved from memory cell. Thus compensated the reference current is achieved without calculating of Trigonometric function.

\section{SIMULATION ANALYSIS OF THE IMPROVED PREDICTIVE CURRENT CONTROL}

In order to evaluate improved predictive current control for PWM rectifier performances, simulation has been carried out using the following parameters: grid voltage $e=380 \mathrm{~V}$, DC-bus voltage $V_{d c}=600 \mathrm{~V}$, equivalent resistance of the loop $R=0.5 \Omega$, AC side inductance $L=5 \mathrm{mH}$, DC-link capacitor $C_{S}=4700 \mu \mathrm{F}$, DC side load $R_{L}=20 \Omega / 10 \Omega$, and the switching frequency $f_{s}=10 \mathrm{KHz}$.

For solving the problem of static phase error existing in the AC side current in traditional predictive current control strategy using periodic phase information of voltage, this paper adopts the improved predictive current control. In order to evaluate the PWM rectifier performances that use two control strategies mentioned above, simulation has been carried out. Fig .6 shows the waveform of A phase voltage and current using traditional method in one period. In the Fig .6(b), the static phase error exists in Waveform of zero-crossing. 


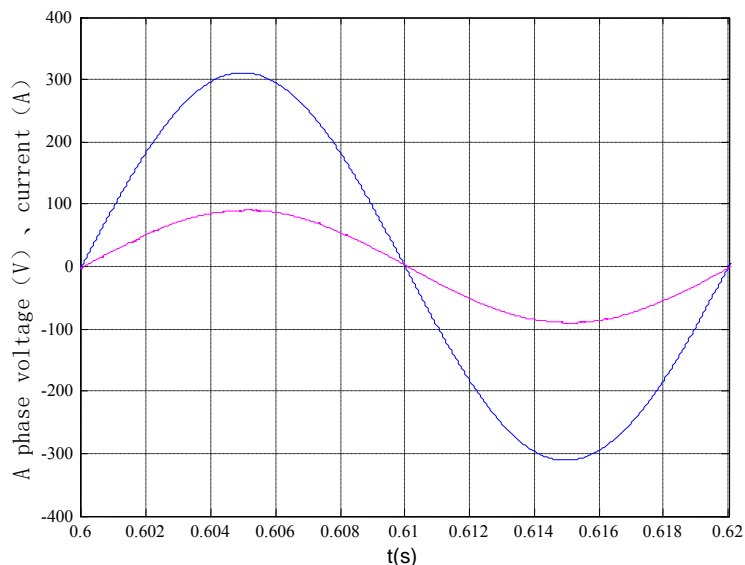

(a) Waveform of one period

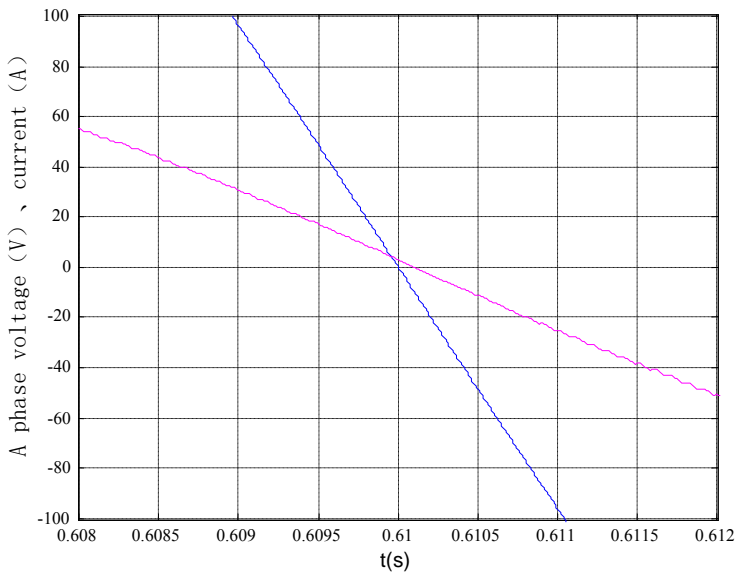

(b) Waveform of zero-crossing

Figure 6. Input current and voltage of phase A using traditional predictive current control

Fig .7 shows the waveform of A phase voltage and current using improved method for compensating phase error in one period. Phase error has been eliminated between voltage and current in zero-crossing using improved predictive current control in Fig .7(b), which compares with Fig .6(b).

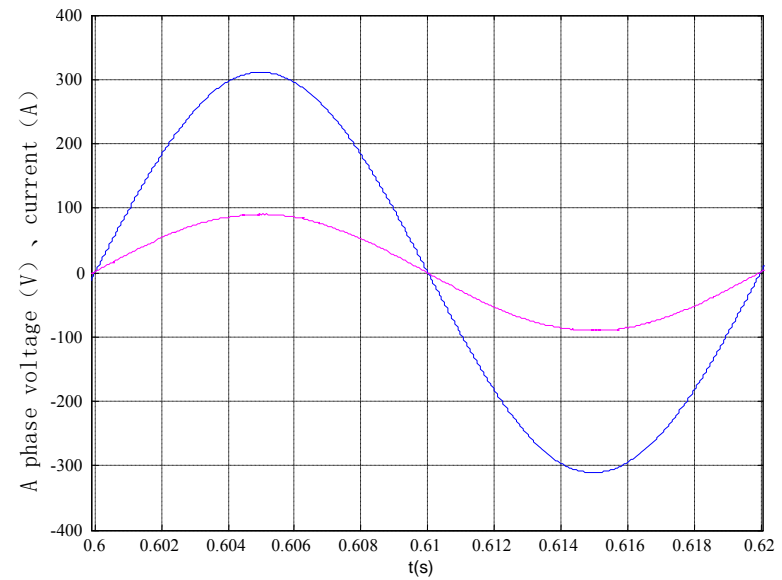

(a) Waveform of one period

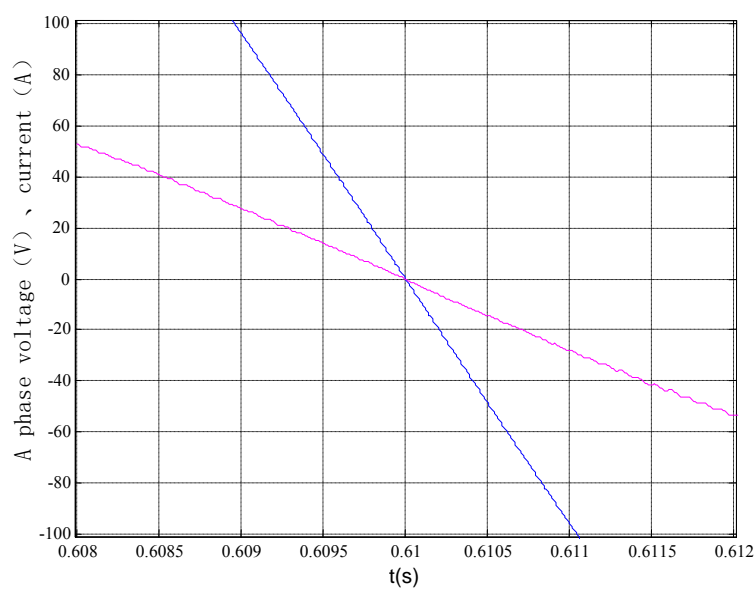

(b) Waveform of zero-crossing

Figure 7. Input current and voltage of phase A using improved predictive current control

Fig .8 shows simulation wave of three-phase voltage source PWM rectifier using improved predictive current control. Fig .8(a) shows the AC current of phase A and DC output voltage at rated load. Fig .8(b) shows the AC current and voltage of phase $\mathrm{A}$ at rated load. Fig .8(c) shows harmonic measurement result of $\mathrm{AC}$ current of phase A.
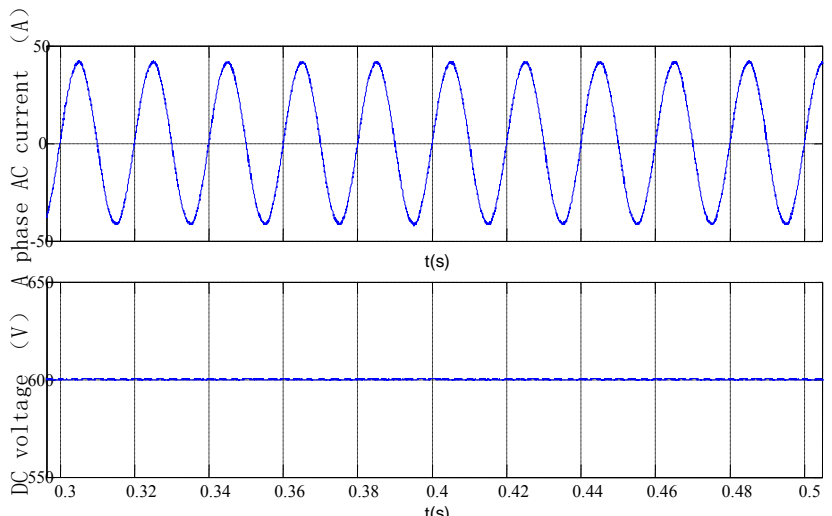

(a) AC current of phase A and DC output voltage at rated load

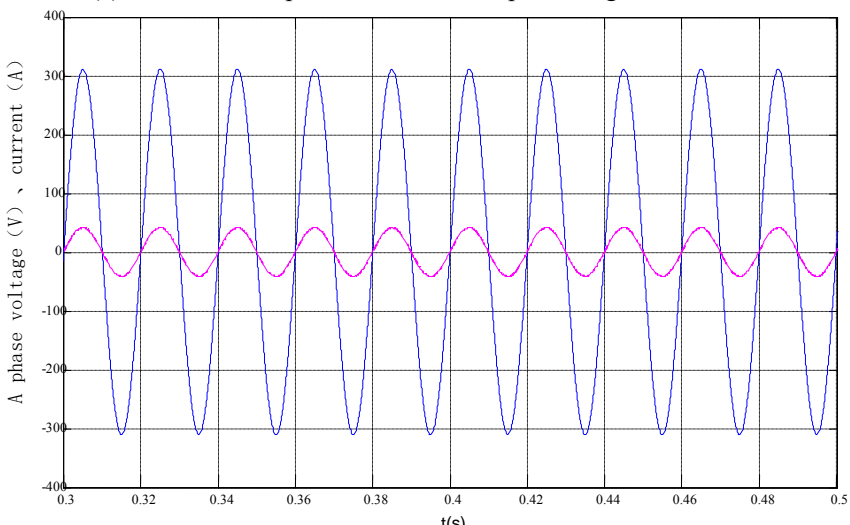

(b) Input current and voltage of phase A at rated load 

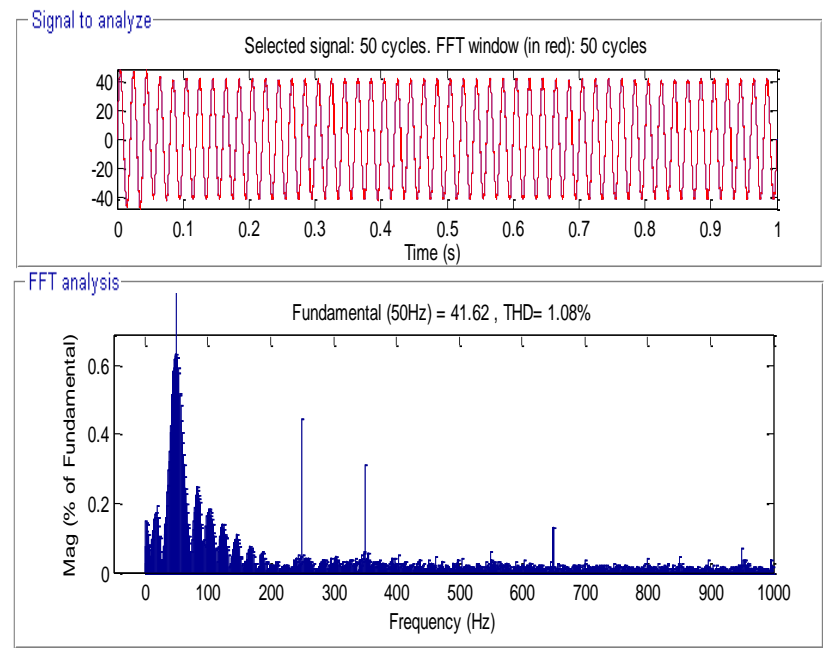

(c) Harmonic measurement result of AC current of phase A

Figure 8. Simulation wave of three-phase voltage source PWM rectifier in steady state

From the simulation results, improved predictive current control strategy can apparently realize the input current tracking input voltage, and unit power factor operation. AC side current is pure sine save, and the harmonic $\mathrm{THD}=1.08 \%$.

\section{CONCLUSIONS}

This paper focuses on predictive current control strategy in two-dimensional stationary $(\alpha-\beta)$ frame, which is Easy for digital realization, but has the problem of static phase error existing in the $\mathrm{AC}$ side current. And the paper analysis the reason of static phase error existing and presents improved predictive current control strategy, which realize static phase error compensation of AC current. Simulation and experimental results confirm the improvement of the proposed control strategy.

\section{ACKNOWLEDGMENT}

This work is supported by" the Fundamental Research Funds for the Central Universities" (NO.3132014045)

\section{REFERENCES}

[1] N.-Y. Dai, M.-C. Wong, F. Ng, and Y.-D. Han, "A FPGA-based generalized pulse width modulator for three-leg center-split and four-leg voltage source inverters," IEEE Trans. Power Electron., vol. 23, no. 3, pp. 1472-1484, May. 2008.

[2] M. Rivera, V. Yaramasu, A. Llor, J. Rodriguez, B. Wu, and M. Fadel, "Digital predictive current control of a three-phase fourleg inverter," IEEE Trans. Ind. Electron., vol. PP, no. 99, p. 1, 2012.

[3] Wang Junrui, "Modeling and Simulation of Three-phase Voltagesource PWM Rectifier with Voltage Space Vector Control," The World of Inverters, Vol. 13, No. 2, pp. 57-59, December 2008.

[4] J. W. Kolar and T. Friedli, "The essence of three-phase PFC rectifier systems-Part I,” IEEE Trans. Power Electron., vol. 28, pp 176-198, Jan. 2013

[5] J. Hu and Z. Q. Zhu, "Improved voltage-vector sequences on dead-beat predictive direct power control of reversible three-phase grid-connected voltage-source converters," IEEE Trans. Power Electron., vol. 28, no. 1, pp. 254-267, Jan. 2013.

[6] T. Soeiro, T. Friedli, and J. W. Kolar, "Three-phase high power factor mains interface concepts for electric vehicle battery charging systems," in Proc. 27th IEEE Appl. Power Electron. Conf. Expo., Feb. 2012, pp. 2603-2610.

[7] F. Liu, B. Wu, N. R. Zargari, and M. Pande, "An active damping method using inductor-current feedback control for high-powe PWM current- source rectifier," IEEE Trans. Power Electron., vol. 26, no. 9, pp. 2580-2587, Sep. 2011.

[8] Yoo, Dae Keun, Wang, Liuping, Rogers, Eric, Paszke and Wojciech "Model predictive control of three phase voltage source converters with an LCL filter," IEEE International Symposium on Industrial Electronics, pp. 562-567, 2014 [Proceedings - 2014 IEEE 23rd International Symposium on Industrial Electronics, ISIE 2014]

[9] M. Rivera, V. Yaramasu, J. Rodriguez, and B. Wu, "Model predictive current control of two-level four-leg inverters - Part II: Experimental implementation and validation," IEEE Trans. Power Electron., vol. 28, no. 7, pp. 3469-3478, Jul. 2013.

[10] Yaramasu, V., Wu, B.; Rivera, M., Rodriguez, J.Y. Yorozu, M Hirano, K. Oka, and Y. Tagawa, "Predictive current control an DC-link capacitor voltages balancing for four-leg NPC inverters," Proceedings of the 2013 IEEE International Electric Machines and Drives Conference, IEMDC 2013, [2013 IEEE International Symposium on Industrial Electronics, ISIE 2013]

[11] Wang, Jiaying, Nademi, Hamed, Norum, Lars, "Control of input current harmonics and output voltage of three-phase voltage source PWM rectifier using Model Predictive Control," IEEE International Symposium on Industrial Electronics, 2013, [2013 IEEE International Symposium on Industrial Electronics, ISIE 2013] 